\title{
Neurological Outcome of Chest Compression-Only Bystander CPR in Asphyxial and Non-Asphyxial Out- of-Hospital Cardiac Arrest: An Observational Study
}

François Javaudin ( $\square$ francois.javaudin@chu-nantes.fr )

Centre Hospitalier Universitaire de Nantes https://orcid.org/0000-0002-7728-2320

Julien Raiffort

CHU Nantes

Natacha Desce

CH Saint-Nazaire

Valentine Baert

University of Lille

Hervé Hubert

University of Lille

Emmanuel Montassier

CHU Nantes

Clément Le Cornec

CHU Nantes

Jean-Baptiste Lascarrou

CHU Nantes

Quentin Le Bastard

CHU Nantes

Original research

Keywords: Basic life support, Cardiopulmonary resuscitation, Out-of-hospital cardiac arrest, Chest compression-only, Mouth-to-mouth resuscitation

Posted Date: September 3rd, 2020

DOl: https://doi.org/10.21203/rs.3.rs-70734/v1

License: (1) (1) This work is licensed under a Creative Commons Attribution 4.0 International License.

Read Full License 
Version of Record: A version of this preprint was published at Prehospital Emergency Care on December 18th, 2020. See the published version at https://doi.org/10.1080/10903127.2020.1852354. 


\section{Abstract}

Background: According to guidelines and bystander skill, two different methods of cardiopulmonary resuscitation (CPR) are feasible: standard CPR (S-CPR) with mouth-to-mouth ventilations and chest compression-only CPR (CO-CPR) without rescue breathing. CO-CPR appears to be most effective for cardiac causes, but there is a lack of evidence for asphyxial causes of out-of-hospital cardiac arrest (OHCA). Thus, the aim of our study was to compare CO-CPR versus S-CPR in adult OHCA from medical etiologies and assess neurologic outcome in asphyxial and non-asphyxial causes.

Methods: Using the French National OHCA Registry (RéAC), we performed a multicenter retrospective study over a five-year period (2013 to 2017). All adult-witnessed OHCA who had benefited from either SCPR or CO-CPR by bystanders were included. Non-medical causes as well as professional rescuers as witnesses were excluded. The primary end point was 30-day neurological outcome in a weighted population for all medical causes, and then for asphyxial, non-asphyxial and cardiac causes.

Results: Of the 8619 subjects included for all medical causes, 6742 had a non-asphyxial etiology, including 5904 of cardiac causes, and 1710 had an asphyxial OHCA. 8.6\%; 95\% Cl [8.1-9.3] of subjects had a good neurological outcome (i.e. cerebral performance category of 1 or 2). Bystanders who performed S-CPR began more often immediately $(89.0 \%$; $95 \% \mathrm{Cl}[87.3-90.5]$ versus $78.2 \%$; $95 \% \mathrm{Cl}[77.2-$ $79.2]$ ) and in younger subjects (64.1 years versus $65.7 ; p<0.001)$. In the weighted population, subjects receiving bystander-initiated CO-CPR had an adjusted relative risk (aRR) of 1.04; $95 \% \mathrm{Cl}$ [0.79-1.38] of having a good neurological outcome at 30 days for all medical causes, 1.28; $95 \% \mathrm{Cl}$ [0.92-1.77] for asphyxial etiologies, $1.08 ; 95 \% \mathrm{Cl}[0.80-1.46]$ for non-asphyxial etiologies and $1.09 ; 95 \% \mathrm{Cl}[0.93-1.28]$ for cardiac-related OHCA.

Conclusions: We observed no significant difference in neurological outcome when lay bystanders of OHCA initiated CO-CPR or S-CPR, whether the cause was asphyxial or not. CO-CPR should probably be promoted in adults because it has many advantages (easier to learn and lower infection risk).

\section{Background}

Early initiated bystander cardiopulmonary resuscitation (CPR) during out-of-hospital cardiac arrest (OHCA) is pivotal with regard to successful outcomes. ${ }^{1,2}$ In Europe, since 2010, two different methods of on-scene CPR have been feasible depending on lay rescuer skills: standard CPR (S-CPR) for trained rescuers and chest compression-only CPR (CO-CPR). ${ }^{3}$ S-CPR consists of administering two mouth-tomouth ventilations every 30 chest compressions (30:2). During CO-CPR, continuous chest compressions are performed without rescue breathing. This technique is easily performed by naïve rescuers guided by a dispatcher and avoids decreases in blood flow secondary to the interruption of chest compressions. ${ }^{4,5}$ The three randomized studies comparing S-CPR and CO-CPR performed by lay bystanders showed no differences in survival after OHCA. ${ }^{6-8}$ However, meta-analyses of these randomized studies showed that CO-CPR was associated with improved survival. ${ }^{9,10}$ Only the randomized study by Rea et al. focused on 
neurological outcome, which was not different between the S-CPR and CO-CPR groups, except in the cardiac cause subgroup where CO-CPR was better. ${ }^{7}$ The results of observational studies have been heterogeneous with regard to neurological outcome. ${ }^{2,11-16}$ Some have reported contradictory results on apparently similar populations, ${ }^{12,16}$ while others excluded asphyxial causes of cardiac arrest. ${ }^{7,11,14,16}$ Failure to provide bystander ventilation for CPR of asphyxial cardiac arrest has not yet been evaluated. Thus, the aim of our study was to compare CO-CPR versus S-CPR in adult OHCA from medical etiologies and assess neurologic outcomes in subgroups of asphyxial and non-asphyxial causes.

\section{Methods}

\section{Study design}

We performed a retrospective cohort study analysis based on data extracted from the French National OHCA Registry (RéAC) from January 12013 to December 31 2017. Only centers that were checked for completeness of OHCA inclusions and data quality regularly controlled were selected for this study. There were 57 of 94 centers meeting this requirement. RéAC is a cohort which includes all OHCA managed by mobile intensive care units (MICU) in France. A MICU consists of an ambulance driver, a nurse and a senior emergency physician as a minimum team. A detailed description of the emergency medical system in France has been previously published. ${ }^{17}$ Briefly, the regional medical dispatching centers (SAMU) receive emergency calls, coordinate the emergency services and assist CPR by telephone. It is a two-tiered pre-hospital system with a fire department ambulance (first professional aid provider) available for prompt intervention and basic life support (BLS), and a mobile emergency and resuscitation service (MERS) including a MICU for advanced life support (ALS). The RéAC form meets the requirements of the French Emergency Medical Service organizations and is structured according to the Utstein universal style. ${ }^{18}$ Data is entered in the secured RéAC database (www.registreac.org). ${ }^{19}$ Several quality controls were performed on this database (online and offline tests).

The present study was approved by the French Advisory Committee on Information Processing in Health Research (CCTIRS) and the French National Data Protection Commission (CNIL, authorization no. 910946). It was approved as a medical assessment registry without requirement for patient consent. ${ }^{19}$

\section{Patient population}

We selected in the RéAC database all witnessed OHCA in adults ( $\geq 18$ years of age) with lay bystanderinitiated cardiopulmonary resuscitation (CPR) before the arrival of professional first responders. Exclusion criteria were unwitnessed OHCA, CPR without chest compressions (ventilation only), OHCA in the presence of professional rescuers and traumatic OHCA. We assessed all medical etiologies of OHCA and classified them in asphyxial and non-asphyxial etiologies, including a subgroup of cardiac causes. The OHCA etiology was determined by the MICU physician in charge of the patient. Subjects were also classified in two groups, according to the bystander-initiated CPR method: chest compression only (CO$\mathrm{CPR}$ ) and chest compression with mouth-to-mouth ventilation (i.e. S-CPR). 


\section{Endpoints}

The primary endpoint was the Glasgow-Pittsburgh Cerebral Performance Categories (CPC) at day 30. Favorable neurological outcome was defined by CPC scores of $\leq 2 .{ }^{20}$ The secondary endpoint was D-30 survival. Outcomes were collected by blinded assessors.

\section{Statistical analyses}

Continuous variables were reported as means with standard deviation (SD) and categorical variables were summed as percentages and $95 \%$ confidence interval $(95 \% \mathrm{Cl})$.

In order to obtain unbiased estimations of the average intervention effects, we used inverse probability of treatment weighting (IPTW). This method was performed in two steps: first, an estimation of the propensity score of intervention (CO-CPR) with a logistic model, and then an estimation of the effect on D-30 neurological outcome, weighted on the propensity score. Covariates included in the model were selected using a univariate analysis of their impact on intervention assignation and on D-30 neurological outcome. Indeed, the inclusion of variables not or weakly correlated to the outcome increases the variance of the effect and is related to low reduction of bias. ${ }^{21}$ The variables included for the propensity score were therefore limited to variables related to the outcome, i.e. whether or not related to exposure (CO-CPR or S-CPR). For each analysis (main and in subgroups), we constructed a different propensity score. In order to minimize the impact of missing data, we performed multiple imputation using chained equations (MICE) with predictive mean matching for continuous data (only one variable included in the propensity score with missing data was imputed: "Time between the emergency call and arrival of first professional rescuers at the scene" with $19.8 \%$ of missing data).

The primary endpoint was assessed with a logistic regression model adjusted on the previously calculated propensity score. Results are expressed as adjusted relative risks with $95 \% \mathrm{Cl}$. Significance was set at $\mathrm{P}<0.05$ and all associations were determined through two-sided testing. Analyses were performed using the R environment (version 3.4.4) in Rstudio software (version 1.2.1335) with the packages mice (version 3.6.0), survey (version 3.35-1) and twang (version 1.5).

\section{Results}

\section{Patient characteristics}

During the five-year study period, $51638 \mathrm{OHCAs}$ were registered in the database from 57 centers. There were $35.1 \%$ unwitnessed OHCA, the bystanders were professional rescuers in $22.7 \%$ of cases and in $22.7 \%$ of the cases no resuscitation was undertaken by non-professional witnesses. Finally, 8619 patients were included, of which 6742 had a non-asphyxial etiology (including 5904 cardiac causes), and 1710 had an asphyxial OHCA etiology (Fig. 1). The main characteristics of the patients are reported in Table 1. Compared to CO-CPR, S-CPR began more often immediately (89.0\%; 95\% Cl [87.3-90.5] versus $78.2 \% ; 95 \% \mathrm{Cl}[77.2-79.2])$ and in younger subjects (64.1 years versus $65.7 ; \mathrm{p}<0.001)$. CPR was 
dispatcher-assisted in 64.5\% 95\% Cl [61.1-67.7] for S-CPR and 77.1\% for CO-CPR 95\% Cl [75.8-78.4]. In the non-asphyxial OHCA group, $17.5 \%$; $95 \% \mathrm{Cl}$ [16.6-18.5] subjects received S-CPR compared to $20.1 \%$; $95 \% \mathrm{Cl}[18.3-22.1]$ in the asphyxial OHCA group. The main baseline characteristics of the sub-groups of patients are reported in Table I in the supplemental material. The proportion bystander-initiated S-CPR was higher at the beginning of the period (linear regression, $P<0.001 ; R^{2}=0.44$ ) (Fig. 2); the same trend was observed in other subgroups (Figure $\mathrm{I}$ in the supplementary material). Simultaneously, the rate of good neurological outcome increased over time (linear regression, $P=0.001 ; R^{2}=0.17$ ) (Fig. 2). In Table II in the supplemental material we reported characteristics of subjects according to neurological outcome and the etiology of OHCA. From some of these variables, we constructed the propensity scores for each group. 
Table 1

Characteristics of patients according to cardiac arrest management by bystanders

\begin{tabular}{|c|c|c|c|}
\hline Characteristic & $\begin{array}{l}\text { S-CPR }(n \\
=1544)\end{array}$ & $\begin{array}{l}\text { CO-CPR }(n \\
=6997)\end{array}$ & $\begin{array}{l}P \\
\text { value }\end{array}$ \\
\hline Age, mean (SD), y & $\begin{array}{l}64.1 \\
(16.7)\end{array}$ & $65.7(15.8)$ & $\begin{array}{l}< \\
0.001\end{array}$ \\
\hline Male, n (\%) & $\begin{array}{l}1057 \\
(68.5)\end{array}$ & $\begin{array}{l}4924 \\
(70.4)\end{array}$ & 0.14 \\
\hline Location, n (\%) & & & $\begin{array}{l}< \\
0.001\end{array}$ \\
\hline Home/Private place & $\begin{array}{l}1047 \\
(67.8)\end{array}$ & $\begin{array}{l}5052 \\
(72.2)\end{array}$ & \\
\hline Public place & $272(17.6)$ & $\begin{array}{l}1211 \\
(17.3)\end{array}$ & \\
\hline Workplace & $56(3.6)$ & $183(2.6)$ & \\
\hline Other & $169(11.0)$ & $551(7.9)$ & \\
\hline \multicolumn{4}{|l|}{ Known medical history, n (\%) } \\
\hline Cardiovascular disease & $655(42.4)$ & $\begin{array}{l}3019 \\
(43.1)\end{array}$ & 0.60 \\
\hline Respiratory disease & $186(12.0)$ & $838(12.0)$ & 0.94 \\
\hline Diabetes & $212(13.7)$ & $903(12.9)$ & 0.38 \\
\hline Cancer & $104(6.7)$ & $515(7.4)$ & 0.39 \\
\hline Alcoholic abuse & $29(1.9)$ & $188(2.7)$ & 0.07 \\
\hline Psychiatric disorder & $58(3.8)$ & $183(2.6)$ & 0.01 \\
\hline Immediate CPR by bystander, $\mathrm{n}(\%)$ & $\begin{array}{l}1374 \\
(89.0)\end{array}$ & $\begin{array}{l}5474 \\
(78.2)\end{array}$ & $\begin{array}{l}< \\
0.001\end{array}$ \\
\hline $\begin{array}{l}\text { Time between emergency call and first professional rescuers } \\
\text { arrival at the scene, mean (SD), min }\end{array}$ & $10.8(6.3)$ & $10.9(5.9)$ & 0.43 \\
\hline Initial shockable cardiac rhythm, n (\%) & $448(29.0)$ & $\begin{array}{l}2260 \\
(32.3)\end{array}$ & 0.01 \\
\hline Presence of gasps, $\mathrm{n}(\%)$ & $135(8.7)$ & $504(7.2)$ & 0.04 \\
\hline Intraosseous injection route during CPR, n (\%) & $66(4.3)$ & $319(4.6)$ & 0.63 \\
\hline Epinephrine dose during CPR, mean (SD), mg & $5.1(4.8)$ & $4.7(4.5)$ & 0.005 \\
\hline
\end{tabular}




\begin{tabular}{|c|c|c|c|}
\hline Characteristic & $\begin{array}{l}\text { S-CPR (n } \\
=1544)\end{array}$ & $\begin{array}{l}\text { CO-CPR (n } \\
=6997)\end{array}$ & $\begin{array}{l}P \\
\text { value }\end{array}$ \\
\hline Inotropic support, n (\%) & $261(16.9)$ & $\begin{array}{l}1148 \\
(16.4)\end{array}$ & 0.63 \\
\hline Impossible endotracheal intubation by MICU, n (\%) & $31(2.0)$ & $77(1.1)$ & 0.004 \\
\hline ECMO, n (\%) & $25(1.6)$ & $167(2.4)$ & 0.07 \\
\hline Targeted temperature management, n (\%) & $200(13.0)$ & $956(13.7)$ & 0.46 \\
\hline D-0 survival, $\mathrm{n}(\%)$ & $501(32.4)$ & $\begin{array}{l}2333 \\
(33.3)\end{array}$ & 0.50 \\
\hline D-30 survival, $\mathrm{n}(\%)$ & $154(10.0)$ & $706(10.1)$ & 0.89 \\
\hline Good neurological outcome at d-30, n (\%) & $134(8.7)$ & $604(8.6)$ & 0.95 \\
\hline Organ donation, $\mathrm{n}(\%)$ & $15(1.0)$ & $113(1.6)$ & 0.01 \\
\hline \multicolumn{4}{|c|}{$\begin{array}{l}\text { Abbreviations: CPR: cardiopulmonary resuscitation; MICU: mobile intensive care unit; ECMO, } \\
\text { extracorporeal membrane oxygenation. } P \text { values were calculated by using the } \chi^{2} \text { test or Student's t- } \\
\text { test. }\end{array}$} \\
\hline
\end{tabular}

\section{Primary and secondary endpoints}

\section{Unweighted population}

On day $30,8.6 \% ; 95 \% \mathrm{Cl}[8.1-9.3]$ of subjects had a good neurological outcome. The details of the CPC are presented in Fig. 3 and Figure II in the supplemental material for the subgroups. There was no significant difference in outcomes between subjects receiving S-CPR or CO-CPR (Table 1 and Table I in the supplemental material for the subgroups).

\section{Weighted population}

The population was successfully weighted (i.e. standardized mean difference $<0.1$ ) for the main analysis and the subgroups analysis (Figure III in the supplemental material). Subjects receiving bystanderinitiated CO-CPR had an adjusted relative risk (aRR) of 1.04; 95\% $\mathrm{Cl}[0.79-1.38]$ of having a good neurological outcome at 30 days (Table 2 ). The aRR for D-30 survival was $1.04 ; 95 \% \mathrm{Cl}[0.79-1.36]$. The aRR of the other subgroups are detailed in the Table 2 and for other variables in the Figure IV in the supplemental material. There was no statistical difference between the two different methods of bystander-initiated CPR for neurological outcome and D-30 survival, whatever the cause of the OHCA. 
Table 2

Adjusted relative risks [ $95 \% \mathrm{Cl}$ ] of $\mathrm{CO}-\mathrm{CPR}$ on the weighted population

\begin{tabular}{|lcc|}
\hline & D-30 survival & Good neurological outcome \\
\hline All medical causes & $1.04[0.79-1.36]$ & $1.04[0.79-1.38]$ \\
\hline Asphyxial causes & $1.21[0.88-1.68]$ & $1.28[0.92-1.77]$ \\
\hline Non-asphyxial causes & $1.06[0.79-1.42]$ & $1.08[0.80-1.46]$ \\
\hline Cardiac causes & $1.06[0.90-1.24]$ & $1.09[0.93-1.28]$ \\
\hline CO-CPR: chest compression-only cardiopulmonary resuscitation \\
\hline
\end{tabular}

\section{Discussion}

From a French OHCA prospective cohort, we evaluated the impact of bystander-initiated CO-CPR on the neurological outcome. We did not observe significant differences in neurological outcomes according to the CPR method performed (S-CPR or CO-CPR), whatever the cause of OHCA (asphyxial or nonasphyxial). These results are consistent with the observations of SOS-KANTO and Rea et al., who did not find differences between CO-CPR and S-CPR in medical OHCAs. ${ }^{2,7}$ Similar results were reported by Panchal et al. in OHCA secondary to non-cardiac causes. ${ }^{13}$ In contrast, Ogawa et al. found that S-CPR was beneficial in OHCA secondary to non-cardiac causes, but not in OHCA secondary to cardiac causes. ${ }^{12}$ Several studies have reported better neurological outcome in subjects who received bystanderinitiated CO-CPR when the etiology of OHCA was a cardiac cause. ${ }^{2,7,11,14}$ Kitamura et al. in a large population showed that CO-CPR was beneficial for medical OHCA (excluding some causes: asphyxia, electrocution, drowning and drug overdose) after one-to-one propensity score matching. ${ }^{16}$ However, they were unable to adjust the results on targeted temperature management (hypothermia), as in other observational studies. ${ }^{2,12-15}$ Nevertheless, it has been clearly established that there is a strong link between this therapy and the neurological outcome, whether or not the rhythm of cardiac arrest is shockable. ${ }^{22-24}$ Here, we were able to adjust the population on this variable, as well as other numerous factors influencing the outcome. Recently Riva et al. found there was an almost a 2-fold higher rate of CPR before EMS arrival and a concomitant 6-fold higher rate of CO-CPR over time but did not collect neurological outcome at day $30 .{ }^{25}$

\section{Lay bystanders are more and more often performing CO- CPR}

From 2013 to 2017, we observed a clear decrease in S-CPR by lay bystanders to the benefit of CO-CPR (reduction of $50 \%$ ). The same trends were observed in Sweden during the same period, ${ }^{25}$ and it has also been observed in other countries. ${ }^{11,15,16}$ Indeed, since 2010, the International Consensus on 
Cardiopulmonary Resuscitation has been encouraging untrained people to carry out CO-CPR, and EMS dispatchers must provide CO-CPR instructions by telephone. ${ }^{26}$ Indeed, in our study there were more dispatcher-assisted CPR in the CO-CPR group and fewer CO-CPR patients received immediate bystander CPR, as it would take time for the dispatcher to explain the mechanics of performing CPR to a bystander. At the end of our study period, there were fewer than $15 \%$ of bystanders performing S-CPR. S-CPR can maybe initiate more frequently without delay as public awareness by movies, and television promote early S-CPR more than CO-CPR.

\section{Learning}

CO-CPR is considered easier to learn and perform. Indeed, at a distance from resuscitation training, the performance of CO-CPR declines only slightly compared to S-CPR. ${ }^{27}$ In addition, a shorter CO-CPR learning program leads to better performance on chest compressions for the general public. ${ }^{28}$ Moreover, the learning of mouth-to-mouth during the COVID-19 pandemic period is an issue. Indeed, the risk of contamination via mannequins is real when mouth-to-mouth is performed by all learners. ${ }^{29}$ Trained people begin CPR more often, resulting in improved OHCA survival. ${ }^{30} \mathrm{CO}-\mathrm{CPR}$ teaching must therefore be preferred and recognized as sufficient to obtain a BLS certificate. ${ }^{29}$

\section{Infectious risk}

Mouth-to-mouth ventilation is a hindrance to the initiation of CPR because of the risk of disease transmission. ${ }^{31,32}$ Even though cases of transmission of infectious diseases are rare (less than 1/200 000), they can occur: Neisseria meningitidis, Mycobacterium tuberculosis, enteric pathogens, herpes simplex virus and probably even severe acute respiratory syndrome-associated coronavirus (SARS$\mathrm{CoV}$ ) ${ }^{33-35}$ It seems logical that mouth-to-mouth ventilation increases the risk of transmission of SARSCoV-2 compared to chest compressions. However, there is no clear evidence that chest compressions result in the generation of aerosol and transmission of infection. ${ }^{36}$

International Liaison Committee on Resuscitation (ILCOR) and the American Heart Association (AHA) suggest that, as long as the COVID-19 pandemic persists, lay rescuers should consider CO-CPR in adult cardiac arrest. ${ }^{37,38}$ Furthermore, in the case of non-household bystander, a face mask or cloth covering the mouth and nose of the rescuer and/or victim should be also considered. ${ }^{37}$ However, COVID-19 may be responsible for acute respiratory distress syndrome (ARDS) requiring mechanical ventilation or even extracorporeal membrane oxygenation (ECMO) ${ }^{39,40}$ As a result, the incidence of asphyxial OHCA is expected to increase significantly. It is precisely in these situations where the administration of early rescue breaths was thought to be beneficial, but our study suggested that CO-CPR performed by lay bystanders in asphyxial OHCA seemed to be at least equivalent to S-CPR with regard to neurological outcomes. 


\section{Non-cardiac cause}

We did not find improved neurological outcome with S-CPR as opposed to CO-CPR and point-estimate indicates possible better outcome for CO-CPR. The results of previous studies on these non-cardiac causes are discordant. Some did not find a difference between CO-CPR and S-CPR, ${ }^{7,13}$ while others showed a superiority of S-CPR. ${ }^{2}$ Another study based on drowning, i.e. hypoxic cardiac arrest, also found no difference between CO-CPR and S-CPR. ${ }^{41}$ Cause of OHCA was classified by physician in charge of patient during prehospital care with history, clinical, and electric information available. The Utstein style consensus define medical cause as cases in which the cause of the cardiac arrest is presumed to be cardiac, other medical cause (eg, anaphylaxis, asthma, gastro-intestinal bleed), and in which there is no obvious cause of the cardiac arrest and asphyxia causes as external causes of asphyxia, such as foreignbody airway obstruction, hanging, or strangulation. ${ }^{18}$ But mechanisms of OHCA can be challenged by this categorization as patient who collapse secondary to hypoxemia related to acute left ventricular congestive heart failure will be categorized as "cardiac" whereas "asphyxia" is the determinant of OHCA and ventilation maybe the first therapeutic option. ${ }^{42}$

Based on our results and previous studies, it can be considered that CO-CPR has many advantages over S-CPR and that it seems logical to continue this CPR practice only in adults, regardless of the cause of medical OHCA, even beyond the COVID-19 pandemic.

\section{Limitations}

First of all, S-CPR and CO-CPR were not assigned by random allocation. In our prospective cohort, we performed an IPTW analysis and made some adjustments for selection bias and confounding factors. Under these conditions, the measured effect was as close as possible to randomized trials. ${ }^{43}$

Second, an inherent limitation of this type of registry analysis is the lack of completeness of data which may have resulted in not being completely exhaustive in the selection of the population. In order to overcome this bias, as explained above, we have only included centers with high quality data. For example, only $0.9 \%$ of the subjects included could not be analyzed due to a lack of neurological outcome $(\mathrm{CPC})$.

Third, the classification of the cause of OHCA was done by the MMT emergency physician. The autopsy data was not available in our registry. This may have led to misclassification of some patients because the causes of OHCA are sometimes difficult to define at an early stage. ${ }^{44}$

Lastly, the quality of bystander-initiated CPR could not be monitored, and we suppose that those who performed S-CPR were more experienced because we observed a higher rate of immediate resuscitation initiation. Moreover, in the case of inexperienced bystanders, the guidelines recommend that medical dispatchers guide the CO-CPR. 


\section{Conclusion}

From our weighted population analysis, we observed no significant differences in neurological outcome when lay bystanders of OHCA initiated CO-CPR or S-CPR. We also specifically analyzed non-asphyxial and asphyxial causes of OHCA, and even in the latter cases mouth-to-mouth ventilation did not improve the outcome. Bystanders should be encouraged to practice CPR, but because of the many advantages of CO-CPR (learning, infection risk), we believe that CO-CPR should probably be promoted.

\section{Abbreviations}

CPR: cardiopulmonary resuscitation; S-CPR: standard CPR; CO-CPR: compression-only CPR; OHCA: out-ofhospital cardiac arrest; RéAC: French National OHCA Registry; Cl: confidence interval; CPC: cerebral performance category; aRR: adjusted relative risk; MICU: mobile intensive care unit; BLS: basic life support; MERS: mobile emergency and resuscitation service; ALS: advanced life support; SD: standard deviation; IPTW: inverse probability of treatment weighting; MICE: multiple imputation using chained equations; SARS-CoV: severe acute respiratory syndrome-associated coronavirus; ILCOR: International Liaison Committee on Resuscitation; AHA: American Heart Association; ARDS: acute respiratory distress syndrome; ECMO: extracorporeal membrane oxygenation

\section{Declarations}

\section{Ethics approval and consent to participate}

This study was approved as a medical registry assessment by the French Advisory Committee on Information Processing in Health Research (CCTIRS), and by the French National Data Protection Commission (CNIL, authorisation number; 910946). This study was approved as a medical registry assessment without the requirement for patient consent.

\section{Consent for publication}

Not applicable

\section{Availability of data and materials}

Data are available on request to the corresponding author.

\section{Competing interests}

The authors declare that they have no competing interests.

\section{Funding}

The RéAC registry is supported by the French Society of Emergency Medicine (SFMU), a patient foundation - Fédération Française de Cardiologie, the Mutuelle Générale de l'Education Nationale 
(MGEN), the University of Lille and the Institute of Health Engineering of Lille.

\section{Authors' contributions}

FJ and QLB had full access to all of the data in the study and take responsibility for the integrity of the data and the accuracy of the data analysis. FJ and QLB elaborated the conception and design of the study. HH and VB collected the data. FJ, JR, ND, CLC and QLB contributed to the analysis and interpretation of the data. FJ wrote the first draft of the paper, with all other authors making important critical revisions. All authors have read and approved the final version of the manuscript.

\section{References}

1. Hasselqvist-Ax I, Riva G, Herlitz J, Rosenqvist M, Hollenberg J, Nordberg P, et al. Early Cardiopulmonary Resuscitation in Out-of-Hospital Cardiac Arrest. N Engl J Med 2015;372(24):23072315.

2. SOS-KANTO study group. Cardiopulmonary resuscitation by bystanders with chest compression only (SOS-KANTO): an observational study. Lancet 2007;369(9565):920-926.

3. Nolan JP, Soar J, Zideman DA, Biarent D, Bossaert LL, Deakin C, et al. European Resuscitation Council Guidelines for Resuscitation 2010 Section 1. Executive summary. Resuscitation 2010;81(10):1219-1276.

4. Sayre MR, Berg RA, Cave DM, Page RL, Potts J, White RD, et al. Hands-only (compression-only) cardiopulmonary resuscitation: a call to action for bystander response to adults who experience outof-hospital sudden cardiac arrest: a science advisory for the public from the American Heart Association Emergency Cardiovascular Care Committee. Circulation 2008;117(16):2162-2167.

5. Berg RA, Sanders AB, Kern KB, Hilwig RW, Heidenreich JW, Porter ME, et al. Adverse hemodynamic effects of interrupting chest compressions for rescue breathing during cardiopulmonary resuscitation for ventricular fibrillation cardiac arrest. Circulation 2001;104(20):2465-2470.

6. Hallstrom A, Cobb L, Johnson E, Copass M. Cardiopulmonary resuscitation by chest compression alone or with mouth-to-mouth ventilation. N Engl J Med 2000;342(21):1546-1553.

7. Rea TD, Fahrenbruch C, Culley L, Donohoe RT, Hambly C, Innes J, et al. CPR with chest compression alone or with rescue breathing. N Engl J Med 2010;363(5):423-433.

8. Svensson L, Bohm K, Castrèn M, Pettersson H, Engerström L, Herlitz J, et al. Compression-only CPR or standard CPR in out-of-hospital cardiac arrest. N Engl J Med 2010;363(5):434-442.

9. Hüpfl M, Selig HF, Nagele P. Chest-compression-only versus standard cardiopulmonary resuscitation: a meta-analysis. Lancet 2010;376(9752):1552-1557.

10. Zhan L, Yang LJ, Huang Y, He Q, Liu GJ. Continuous chest compression versus interrupted chest compression for cardiopulmonary resuscitation of non-asphyxial out-of-hospital cardiac arrest. Cochrane Database Syst Rev 2017;3:CD010134. 
11. Bobrow BJ, Spaite DW, Berg RA, Stolz U, Sanders AB, Kern KB, et al. Chest compression-only CPR by lay rescuers and survival from out-of-hospital cardiac arrest. JAMA 2010;304(13):1447-1454.

12. Ogawa T, Akahane M, Koike S, Tanabe S, Mizoguchi T, Imamura T. Outcomes of chest compression only CPR versus conventional CPR conducted by lay people in patients with out of hospital cardiopulmonary arrest witnessed by bystanders: nationwide population based observational study. BMJ 2011;342:c7106.

13. Panchal AR, Bobrow BJ, Spaite DW, Berg RA, Stolz U, Vadeboncoeur TF, et al. Chest compression-only cardiopulmonary resuscitation performed by lay rescuers for adult out-of-hospital cardiac arrest due to non-cardiac aetiologies. Resuscitation 2013;84(4):435-439.

14. Iwami T, Kitamura T, Kawamura T, Mitamura H, Nagao K, Takayama M, et al. Chest compression-only cardiopulmonary resuscitation for out-of-hospital cardiac arrest with public-access defibrillation: a nationwide cohort study. Circulation 2012;126(24):2844-2851.

15. Iwami T, Kitamura T, Kiyohara K, Kawamura T. Dissemination of Chest Compression-Only Cardiopulmonary Resuscitation and Survival After Out-of-Hospital Cardiac Arrest. Circulation 2015;132(5):415-422.

16. Kitamura T, Kiyohara K, Nishiyama C, Kiguchi T, Kobayashi D, Kawamura T, et al. Chest compressiononly versus conventional cardiopulmonary resuscitation for bystander-witnessed out-of-hospital cardiac arrest of medical origin: A propensity score-matched cohort from 143,500 patients. Resuscitation 2018;126:29-35.

17. Adnet F, Lapostolle F. International EMS systems: France. Resuscitation 2004;63(1):7-9.

18. Perkins GD, Jacobs IG, Nadkarni VM, Berg RA, Bhanji F, Biarent D, et al. Cardiac arrest and cardiopulmonary resuscitation outcome reports: update of the Utstein Resuscitation Registry Templates for Out-of-Hospital Cardiac Arrest: a statement for healthcare professionals from a task force of the International Liaison Committee on Resuscitation (American Heart Association, European Resuscitation Council, Australian and New Zealand Council on Resuscitation, Heart and Stroke Foundation of Canada, InterAmerican Heart Foundation, Resuscitation Council of Southern Africa, Resuscitation Council of Asia); and the American Heart Association Emergency Cardiovascular Care Committee and the Council on Cardiopulmonary, Critical Care, Perioperative and Resuscitation. Circulation 2015;132(13):1286-1300.

19. Hubert H, Tazarourte K, Wiel E, Zitouni D, Vilhelm C, Escutnaire J, et al. Rationale, methodology, implementation, and first results of the French out-of-hospital cardiac arrest registry. Prehosp Emerg Care 2014;18(4):511-519.

20. Becker LB, Aufderheide TP, Geocadin RG, Callaway CW, Lazar RM, Donnino MW, et al. Primary outcomes for resuscitation science studies: a consensus statement from the American Heart Association. Circulation 2011;124(19):2158-2177.

21. Brookhart MA, Schneeweiss S, Rothman KJ, Glynn RJ, Avorn J, Stürmer T. Variable selection for propensity score models. Am J Epidemiol 2006;163(12):1149-1156. 
22. Bernard SA, Gray TW, Buist MD, Jones BM, Silvester W, Gutteridge G, et al. Treatment of comatose survivors of out-of-hospital cardiac arrest with induced hypothermia. N Engl J Med 2002;346(8):557-563.

23. Hypothermia after Cardiac Arrest Study Group. Mild therapeutic hypothermia to improve the neurologic outcome after cardiac arrest. N Engl J Med 2002;346(8):549-556.

24. Lascarrou J-B, Merdji H, Le Gouge A, Colin G, Grillet G, Girardie P, et al. Targeted Temperature Management for Cardiac Arrest with Nonshockable Rhythm. N Engl J Med 2019;381(24):23272337.

25. Riva G, Ringh M, Jonsson M, Svensson L, Herlitz J, Claesson A, et al. Survival in Out-of-Hospital Cardiac Arrest After Standard Cardiopulmonary Resuscitation or Chest Compressions Only Before Arrival of Emergency Medical Services: Nationwide Study During Three Guideline Periods. Circulation 2019;139(23):2600-9.

26. Hazinski MF, Nolan JP, Billi JE, Böttiger BW, Bossaert L, de Caen AR, et al. Part 1: Executive summary: 2010 International Consensus on Cardiopulmonary Resuscitation and Emergency Cardiovascular Care Science With Treatment Recommendations. Circulation 2010;122(16 Suppl 2):S250-275.

27. Heidenreich JW, Sanders AB, Higdon TA, Kern KB, Berg RA, Ewy GA. Uninterrupted chest compression CPR is easier to perform and remember than standard CPR. Resuscitation 2004;63(2):123-130.

28. Nishiyama C, Iwami T, Kawamura T, Ando M, Yonemoto N, Hiraide A, et al. Effectiveness of simplified chest compression-only CPR training for the general public: a randomized controlled trial. Resuscitation 2008;79(1):90-96.

29. Baldi E, Contri E, Savastano S, Cortegiani A. The Challenge of Laypeople Cardio-pulmonary Resuscitation Training during and after COVID-19 Pandemic. Resuscitation 2020;152:3-4.

30. Bray JE, Straney L, Smith K, Cartledge S, Case R, Bernard S, et al. Regions With Low Rates of Bystander Cardiopulmonary Resuscitation (CPR) Have Lower Rates of CPR Training in Victoria, Australia. J Am Heart Assoc 2017;6(6).

31. Locke CJ, Berg RA, Sanders AB, Davis MF, Milander MM, Kern KB, et al. Bystander cardiopulmonary resuscitation. Concerns about mouth-to-mouth contact. Arch Intern Med 1995;155(9):938-943.

32. Baldi E, Bertaia D, Savastano S. Mouth-to-mouth: an obstacle to cardiopulmonary resuscitation for lay-rescuers. Resuscitation 2014;85:e195-6.

33. Mejicano GC, Maki DG. Infections acquired during cardiopulmonary resuscitation: estimating the risk and defining strategies for prevention. Ann Intern Med 1998;129(10):813-828.

34. Liu W, Tang F, Fang L-Q, Vlas SJD, Ma H-J, Zhou J-P, et al. Risk factors for SARS infection among hospital healthcare workers in Beijing: a case control study. Tropical Medicine \& International Health 2009;14(s1):52-59.

35. Christian MD, Loutfy M, McDonald LC, Martinez KF, Ofner M, Wong T, et al. Possible SARS coronavirus transmission during cardiopulmonary resuscitation. Emerging Infect Dis 2004;10(2):287-293. 
36. Couper K, Taylor-Phillips S, Grove A, Freeman K, Osokogu O, Court R, et al. COVID-19 in cardiac arrest and infection risk to rescuers: A systematic review. Resuscitation 2020;151:59-66.

37. Edelson DP, Sasson C, Chan PS, Atkins DL, Aziz K, Becker LB, et al. Interim Guidance for Basic and Advanced Life Support in Adults, Children, and Neonates With Suspected or Confirmed COVID-19: From the Emergency Cardiovascular Care Committee and Get With the Guidelines®-Resuscitation Adult and Pediatric Task Forces of the American Heart Association in Collaboration with the American Academy of Pediatrics, American Association for Respiratory Care, American College of Emergency Physicians, The Society of Critical Care Anesthesiologists, and American Society of Anesthesiologists: Supporting Organizations: American Association of Critical Care Nurses and National EMS Physicians. Circulation 2020;141(25):e933-43.

38. Perkins GD, Morley PT, Nolan JP, Soar J, Berg K, Olasveengen T, et al. International Liaison Committee on Resuscitation: COVID-19 Consensus on Science, Treatment Recommendations and Task Force Iconsensus on science, treatment recommendations and task force insights. Resuscitation 2020;151:145-7.

39. Lai C-C, Shih T-P, Ko W-C, Tang H-J, Hsueh P-R. Severe acute respiratory syndrome coronavirus 2 (SARS-CoV-2) and coronavirus disease-2019 (COVID-19): The epidemic and the challenges. Int J Antimicrob Agents 2020;55(3):105924.

40. Richardson S, Hirsch JS, Narasimhan M, Crawford JM, McGinn T, Davidson KW, et al. Presenting Characteristics, Comorbidities, and Outcomes Among 5700 Patients Hospitalized With COVID-19 in the New York City Area. JAMA 2020; 323(20):2052-9.

41. Fukuda T, Ohashi-Fukuda N, Hayashida K, Kondo Y, Kukita I. Bystander-initiated conventional vs compression-only cardiopulmonary resuscitation and outcomes after out-of-hospital cardiac arrest due to drowning. Resuscitation 2019;145:166-74.

42. Varvarousis D, Varvarousi G, lacovidou N, D'Aloja E, Gulati A, Xanthos T. The pathophysiologies of asphyxial vs dysrhythmic cardiac arrest: implications for resuscitation and post-event management. Am J Emerg Med 2015;33(9):1297-304.

43. Austin PC. The use of propensity score methods with survival or time-to-event outcomes: reporting measures of effect similar to those used in randomized experiments. Stat Med 2014;33(7):12421258.

44. Pokorna M, Necas E, Skripsky R, Kratochvil J, Andrlik M, Franek O. How accurately can the aetiology of cardiac arrest be established in an out-of-hospital setting? Analysis by "concordance in diagnosis crosscheck tables." Resuscitation 2011;82(4):391-7.

\section{Figures}




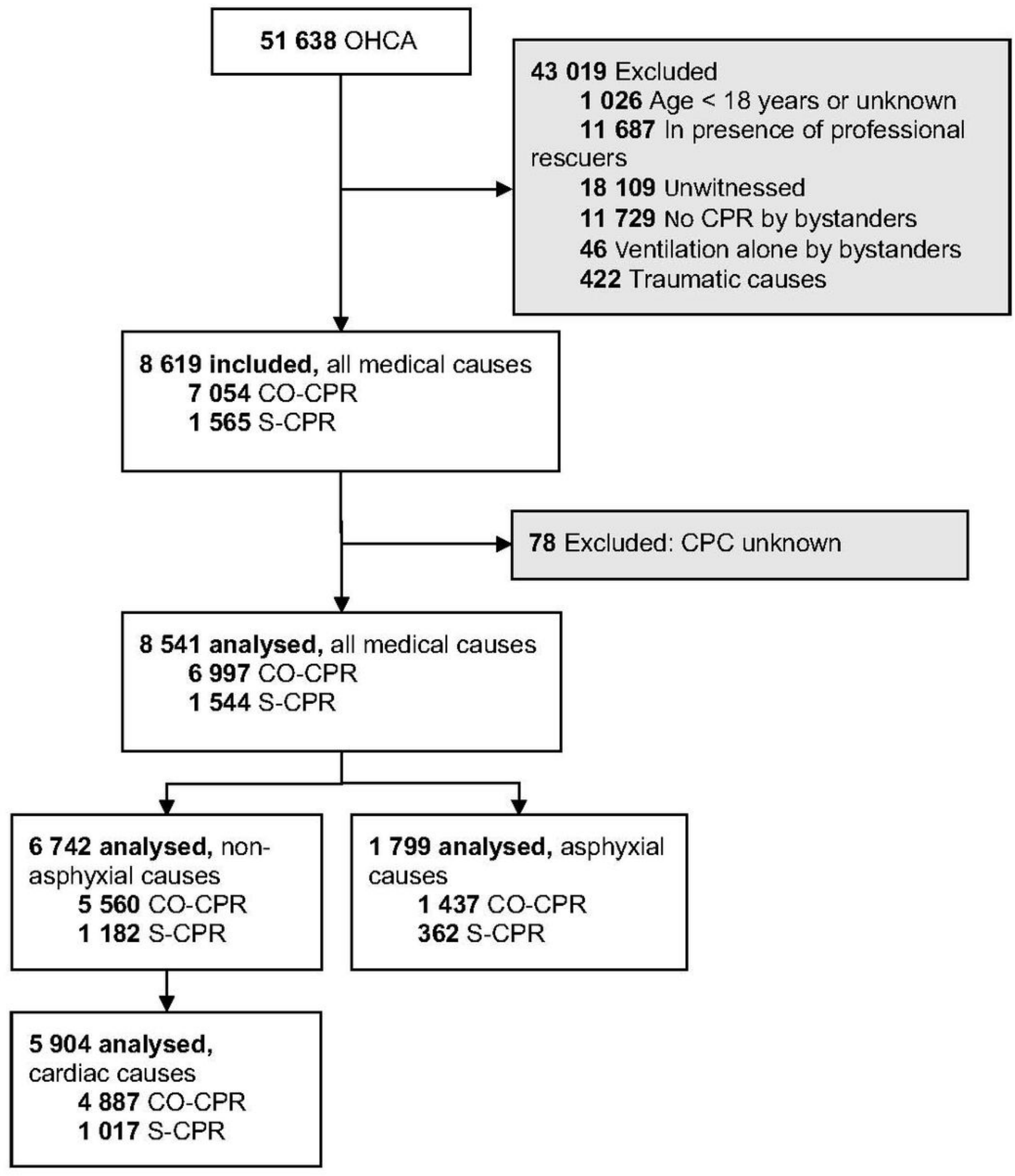

Figure 1

Flow chart of patient inclusion OHCA, out-of-hospital cardiac arrest; CO-CPR, chest compression-only cardiopulmonary resuscitation; S-CPR standard cardiopulmonary resuscitation; CPC, Cerebral Performance Categories 


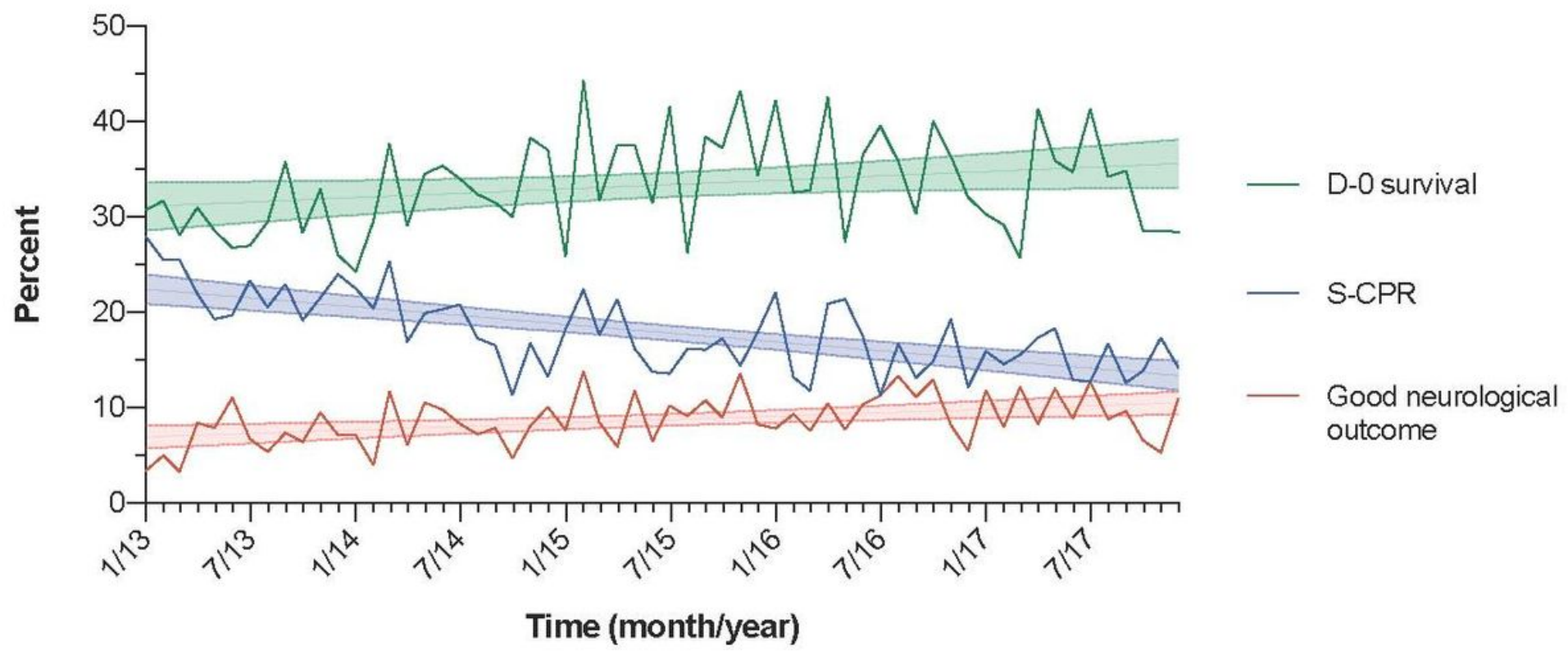

Figure 2

Percentage and linear regression (95\% confidence interval) of S-CPR, D0-survival and D-30 neurological outcome, by month CO-CPR, chest compression-only cardiopulmonary resuscitation; S-CPR standard cardiopulmonary resuscitation. Favorable neurologic outcome was defined as a CPC score of 1 (good cerebral performance or minor disability) or 2 (moderate disability)

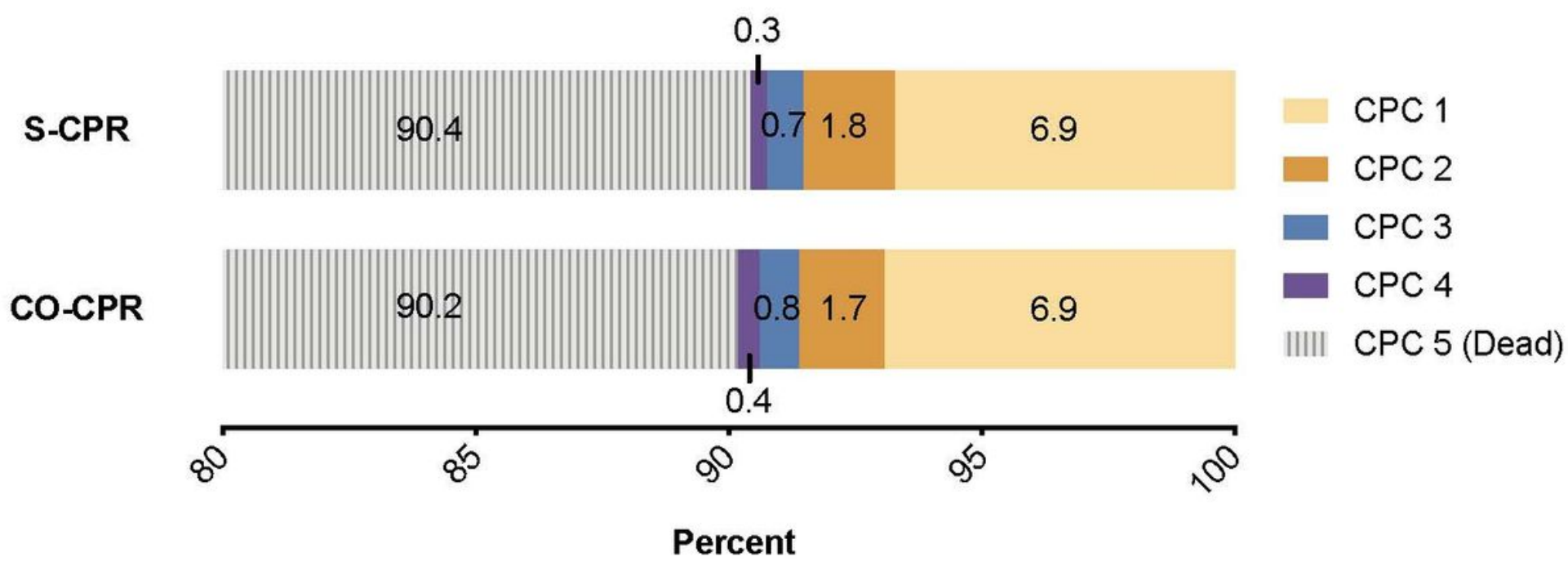

Figure 3

Distribution of Cerebral Performance Categories on day 30 after cardiac arrest (all medical causes). COCPR, chest compression-only cardiopulmonary resuscitation; S-CPR standard cardiopulmonary resuscitation; CPC, Cerebral Performance Categories (favorable neurologic outcome was defined as a CPC score of 1 (good cerebral performance or minor disability) or 2 (moderate disability))

\section{Supplementary Files}


This is a list of supplementary files associated with this preprint. Click to download.

- supplementarymaterial.pdf

- supplementarymaterial.pdf

- supplementarymaterial.pdf 